\title{
The effect of push factors in the leisure sports participation of the retired elderly on re-socialization recovery resilience
}

\author{
Kwang-Uk Lee ${ }^{1, *}$, Hong-Rok Kim', Eun-Surk Yi ${ }^{2}$ \\ ${ }^{1}$ Department of Exercise \& Health, College of Arts \& Physical Education, Incheon National University, Incheon, Korea \\ ${ }^{2}$ Department of Exercise Rehabilitation \& Welfare, College of Health Science, Gachon University, Incheon, Korea
}

This study aimed to provide useful materials for the realization of healthy and happy welfare society through the re-socialization of the retired elderly by identifying the effect of the push factors in the leisure sports participation of the retired elderly on re-socialization and recovery resilience. To achieve the study purpose, 304 subjects over the age of 55 residing in Seoul and Gyeonggin among the retired elderly were selected by using the method of systematic stratified cluster random sampling. As research methods, questionnaire papers were used. The data were collected and data which were judged to be incomplete or unreliable in responses were excluded from the analysis. After inputting data which are available to analysis and SPSS 18.0 program was used for statistical techniques. In this, data were processed by factor analysis, correlation analysis, and multiple regression analysis. The study re- sults that were obtained from this analysis are as follows: First, the psychological stability among the push factors in the leisure sports participation of the elderly had a significant effect on re-socialization, while health pursuit had a significant effect on personal exchange and economic activity among the sub-factors of re-socialization. Second, psychological stability among the push factors in the leisure sports participation of the retired elderly had a significant effect on recovery resilience; personal relationships had an effect on empathy skills, impulse control, and self-efficacy; and health pursuit had a significant effect on impulse control, optimism, and self-efficacy.

Keywords: Retired elderly, Push factors, Leisure sports participation, Re-socialization, Recovery resilience

\section{INTRODUCTION}

Our society is currently faced with the problems of the elderly due to the rapid aging which is unprecedented in the wake of the increase of life expectancy. Also, the prolongation of the average life expectancy and the drastic increase of early retirement have changed the quality and forms of life in old age. The old age is the period which accounts for a fourth in the length of human life. Since this length of old age has been prolonged, it is needed to switch the perspectives about the meaning of old age from the modest view which regards the old age as an additional time in life to the assertive view which sees the old age as the time of complete maturity in human life.

The average retirement age in Korean companies is about 56.9.
The mandatory retirement system is chosen by a total of $95.9 \%$ of the whole companies. However, due to the influence of the International Monetary Fund (IMF) in the end of 1997, retirement age became shorter with the age of around 54 on average and only $12 \%$ of retired people are subject to the regular retirement.

This social reality implies that the preparation for a later life after retirement is keenly required in both personal and social aspects. However, the employment rate of early retirees in Korea was extremely low with $5.48 \%$ in contrast to the increase of early retirees. In addition, early retirement is likely to go into the permanent retirement. However, it is a state that the institutional preparation for retirees is not sufficiently equipped both personally and socially. Therefore, financial preparation such as pension and medical costs, re-employment, and sound leisure sports are
${ }^{*}$ Corresponding author: Kwang-Uk Lee

Department of Exercise \& Health, College of Arts \& Physical Education, Incheon National University, 119 Academy-ro, Yeonsu-gu, Incheon 406-772, Korea Tel: +82-32-813-9295, Fax: +82-32-835-0715, E-mail: kwlee680223@hanmail.net Received: February 4, 2014 / Revised: February 21, 2014 / Accepted: April 14, 2014
This is an Open Access article distributed under the terms of the Creative Commons Attribution Non-Commercial License (http://creativecommons.org/licenses/by-nc/3.0/) which permits unrestricted non-commercial use, distribution, and reproduction in any medium, provided the original work is properly cited. 
needed for a healthy and happy life after retirement. The preparation for old age after retirement is the crucial task in our reality, which cannot be procrastinated.

The aging issues have caused a lot of problems in our society. In particular, as people get older, they usually experience the worsening of health status due to the physical and physiological decline, the reduction of income as a result of children's marriage and retirement, and the loss of their role at home and society in accordance with the nuclear family system and the loss of the social bond. In addition, Social retirement leads to depression, alienation, emptiness, mental fragility because retired people inevitably spend a weary life. Furthermore, the deterioration or impairment of physical and mental function as well as the death of friends performs a great role in lowering the happiness of the elderly (Lee and An, 2010). However, unfortunately, the social and psychological isolation and alienation and cultural infrastructure, which can deal with the health problems of retired men, the sharp increase in leisure time caused by a halt of economic activity, and the collapse of family structure, have not been established yet in our society. Accordingly, the elderly issue has emerged as a national problem going beyond individual problems. In this regard, the endeavor to enjoy the high-quality life in old age should be made both individually and socially to attract the policies of the government (Kim and Kang, 2006).

The early study about recovery resilience began by analyzing the characteristics of those who were born in the poor island called Kauai, Hawai and grew as warm-hearted people by overcoming poor conditions such as the absence of parents, diseases, and disability. However, even if petty stress in daily lives which is not a serious condition is accumulated, it will be a risk factor or can have a negative effect on life.

Consequently, it was revealed that a person with high recovery resilience would be higher in the attention control and emotional control, while a person with low recovery resilience would show greater depression and stress when they make mistakes. Like this, recovery resilience can help people maintain their physical and mental health even against trivial stress in daily lives apart from serious problems such as disability, bankruptcy, and drug abuse. Therefore, recovery resilience is the ability which is required for the re-socialization of the retired elderly and the basic factor of happiness and success, influencing job performance, physical health, mental health, and the quality of relationships.

In this context, this study sees recovery resilience as the process of re-socialization which means returning from difficult or stressful condition to the adaptive condition, which is based on the concept of combining 'recovery,' and 'the improvement of psychological resistibility called 'resilience' representing growth, according to the definition of Shin et al. (2009).

In the meantime, numerous studies on the elderly have been conducted to provide the necessary clue to the elderly issues in all academic areas so far. In particular, the main topics are about a wide range of mental factors and the mediating effect of recovery resilience such as stress, social support, subjective well-being, self-esteem, loneliness, mental happiness, and life quality. In accordance with such trends, numerous studies have been conducted in the study field of physical education.

First of all, studies have been conducted with the themes of loneliness according to the leisure sports participation of the elderly (Lee and Keon, 2003), leisure satisfaction (Choi et al., 2007), depression (Park et al., 2007), mental happiness (Jung and Won, 2010), social support (Seong and Back, 2004), social network (Seo, 2000), social support and self-esteem (Choi, 2007), and relationship between social support and satisfaction in sports and loneliness (Kim and Yun, 2007). This study examined the effect of the leisure sports participation of the elderly on successful aging around mediating effect and buffering effect of recovery resilience (Lee and An, 2010), the relationship between life stress and depression according to the participation in leisure sports (Choi and Lee, 2012), and the correlation between the participation of the Korean elderly in leisure activities and well-being (Lee, 2012). The study results showed that recovery resilience would play a crucial role in successful aging, the reduction of life stress and a better life quality.

A large number of studies revealed that the participation of the elderly in leisure sports would have a positive effect on the health of the elderly and the improvement of their life quality. Put simply, it is indicated that the elderly who participate in leisure activity are healthier in terms of cognition, behavior, psychology, social involvement, and physical and medical health. Accordingly, their happiness and recovery resilience were higher and their social involvement was more active in comparison with the elderly who do not participate in leisure sports. Therefore, it is judged that re-socialization will resolve the social problems of the retired elderly. However, studies on recovery resilience, changing adversity into a good luck by returning from stressful situation or the difficulty of re-socialization to the adaptive condition as a result of the participation in leisure sports should be complemented.

In this regard, this study aimed to provide the useful materials for the health of the elderly, which are available to the embodiment of a healthy and happy welfare society through the re-social- 
ization of the retired elderly by identifying the effect of re-socialization and the push factors in the leisure sports participation on recovery resilience and analyzing the relationships of the push factors of the leisure sports participation of the elderly, re-socialization, and recovery resilience.

To achieve the study purpose, the study questions for the specific resolution are set as follows: First, the push factors in the leisure sports participation may be correlated to the re-socialization and recovery resilience of the retired elderly. Second, there might be a difference in re-socialization according to the push factors in the leisure sports participation. Third, there might be a difference in recovery resilience according to the push factors in the leisure sports participation.

\section{MATERIALS AND METHODS}

\section{Research subjects}

To verify the effect of the push factors in the leisure sports participation of the retired elderly, this study targeted at the elderly over the age of 55, currently residing in Seoul and Gyeongin in 2011 as of 2011 and selected the samples by using the systematic stratified cluster random sampling. First of all, the number of samples was set according to the gender of people over the age of 55 residing in Seoul and Gyeongin and the locations of leisure sports centers were divided into Gangnam and Gangbuk in Seoul, Gyeongin-region, Namgu and Yeonsu-gu to draw up the sampling framework. The selected subjects were 320 , and 16 subjects were omitted due to the reasons of incomplete response and contents in the surveys. Therefore, finally 304 subjects were selected. The characteristics of the concrete study subjects are shown in Table 1.

\section{Investigation tools}

Questionnaire papers are the tools for the data collection in this study. In terms of question contents, background variables include 6 questions; gender, household income, health status, the participation frequency in leisure sports, period, and intensity. The questionnaire contents that include 6 background variables are comprised of a total of 36 questions with 9 questions in the push factors in the leisure sports participation, 9 questions in re-socialization, and 12 questions in recovery resilience.

Each measure was composed in accordance with the study purpose in consultation with the panel of expert, and each questionnaire paper was used through the preliminary investigation. The factors of re-socialization were questioned by Bae (2004).

To measure recovery resilience, questions, developed by Reivich
Table 1. The general characteristics of study subjects

\begin{tabular}{|c|c|c|c|}
\hline Variables & Division & Frequency & $\%$ \\
\hline \multirow[t]{3}{*}{ Age (yr) } & Less than 65 & 256 & 84.2 \\
\hline & $65-70$ & 32 & 10.5 \\
\hline & Over 70 & 16 & 5.3 \\
\hline \multirow[t]{5}{*}{ Household income } & Less than 200 & 16 & 5.3 \\
\hline & Less than 300 & 48 & 15.8 \\
\hline & Less than 400 & 48 & 15.8 \\
\hline & Less than 500 & 80 & 26.3 \\
\hline & Over 600 & 112 & 36.8 \\
\hline \multirow[t]{3}{*}{ Health status } & Good & 64 & 21.1 \\
\hline & Average & 176 & 57.8 \\
\hline & Weak & 64 & 21.1 \\
\hline \multirow[t]{4}{*}{ Participation frequency } & 1 & 160 & 52.6 \\
\hline & $2-3$ & 96 & 31.6 \\
\hline & $4-5$ & 32 & 10.5 \\
\hline & Over 6 days & 16 & 5.3 \\
\hline \multirow[t]{4}{*}{ Participation time } & $30 \mathrm{~min}$ & 96 & 31.6 \\
\hline & $1 \mathrm{~h}$ & 80 & 26.3 \\
\hline & $1 \mathrm{~h}$ and $30 \mathrm{~min}$ & 64 & 21.1 \\
\hline & $2 \mathrm{~h}$ & 64 & 21.1 \\
\hline \multirow[t]{4}{*}{ Participation duration } & Less than 2 & 96 & 31.6 \\
\hline & Less than 5 & 80 & 26.3 \\
\hline & Less than 10 & 96 & 31.6 \\
\hline & Over 10 & 32 & 10.5 \\
\hline
\end{tabular}

and Shatte (2003) and Jeon (2010), were used by being revised and complemented in accordance with the purpose of this study. The questions of recovery resilience consist of 12 questions; 3 questions in optimism, 3 questions in empathy skills, 3 questions in self-efficacy, and 3 questions in impulse control. The Likert Scale was used to measure the questions about the push factors of the leisure sports participation of the retired elderly on re-socialization and recovery resilience, and the response was calculated as 1 point in "Not at all," and 5 points in "strongly agree."

\section{Validity and reliability}

To examine the validity of questionnaire papers in this study, expert meeting was held with two professors in the department of health management, one Ph.D. degree earner in sports sociology, and one Ph.D degree earner in sports rehabilitation. After the investigation of questions, this expert group discussed the validity of contents and the fitness of questions, and modified and complemented the inadequate points.

To verify the validity of the measurement tools, the exploratory factor analysis was conducted. To minimize the number of factors, the principle component analysis was used. Among the rotation 
methods varimax rotation method was used and the factor over 1 in eigen value was extracted, while, the commonality was identified with over 0.5 in all items.

First, 3 factors were selected in the study results of factor analysis with 9 questions concerning the push factors in the leisure sports participation. The overall explanatory power with the exception of 2 questions, which are low in the factor eigen value was illustrated in Table 2. To verify the reliability, Cronbach's Alpha, which is the confidence coefficient representing the internal consistency was calculated. Cronbach's Alpha appeared to be $0.777-$ 0.886 , similar to the level (0.819-0.863) of the previous studies.

Table 2. The factor analysis of the participation push and the analysis of reliability

\begin{tabular}{|c|c|c|c|}
\hline \multirow{2}{*}{ Questions } & \multicolumn{3}{|c|}{ Push factors of leisure sports } \\
\hline & Mental & Relationship & Health \\
\hline $\begin{array}{l}\text { 1. I participate in sports leisure to forget the } \\
\text { current problems. }\end{array}$ & 0.894 & 0.168 & -0.121 \\
\hline $\begin{array}{l}\text { 4. I participate in leisure sports for life } \\
\text { relaxation. }\end{array}$ & 0.773 & 0.380 & -0.269 \\
\hline $\begin{array}{l}\text { 10. I participate in leisure sports for } \\
\text { comfortable life. }\end{array}$ & 0.881 & 0.179 & 0.318 \\
\hline $\begin{array}{l}\text { 8. I participate in leisure sports for joining } \\
\text { others. }\end{array}$ & 0.301 & 0.880 & 0.105 \\
\hline 11. I participate in leisure sports for affiliation & 0.235 & 0.838 & -0.077 \\
\hline $\begin{array}{l}\text { 3. I participate in leisure activity for physical } \\
\text { health. }\end{array}$ & -0.211 & 0.252 & 0.805 \\
\hline $\begin{array}{l}\text { 6. I participate in leisure sports for life vitality } \\
\text { and stimulation. }\end{array}$ & 0.223 & -0.425 & 0.749 \\
\hline Eigen value & 4.127 & 1.755 & 1.572 \\
\hline Dispersion rate & 41.272 & 17.552 & 15.722 \\
\hline Accumulation (\%) & 41.272 & 58.824 & 74.546 \\
\hline Reliability & 0.886 & 0.862 & 0.777 \\
\hline
\end{tabular}

This was judged to be reasonable.

As a result of factor analysis of 9 questions with regard to the re-socialization factors, 3 factors were extracted and 2 questions, whose eigen value is low, were excluded. Therefore, overall explanatory power was 83.554. The results are shown in Table 3. To verify reliability, Cronbach's Alpha, which is the confidence coefficient representing the internal consistency was calculated. Cronbach's Alpha appeared to be $0.680-0.739$, similar to the level (0.9190.963 ) of the previous studies. This was judged to be reasonable.

As a result of factor analysis of 12 questions with regard to recovery resilience, 4 factors were drawn, 3 questions, which are low in the factor eigen value, were excluded, so that overall explanatory power was $90.262 \%$. The results are indicated in Table 4 . To verify

Table 3. The factor analysis of re-socialization and the analysis of reliability

\begin{tabular}{lrrc}
\hline & \multicolumn{3}{c}{ Re-socialization } \\
\cline { 2 - 4 } Questions & Exchange & $\begin{array}{c}\text { Economic } \\
\text { activity }\end{array}$ & $\begin{array}{c}\text { Social } \\
\text { commitment }\end{array}$ \\
\hline $\begin{array}{l}\text { 6. I think that I have many things to do } \\
\text { socially. }\end{array}$ & $\mathbf{0 . 8 2 3}$ & -0.265 & 0.220 \\
5. I can buy a meal or coffee for my friends. & $\mathbf{0 . 7 9 5}$ & 0.367 & 0.261 \\
$\begin{array}{l}\text { 4. I think that my personal relationships tend } \\
\text { to be round. }\end{array}$ & $\mathbf{0 . 6 2 8}$ & 0.278 & 0.428 \\
$\begin{array}{l}\text { 1. Currently, I don't have any financial } \\
\text { problem. }\end{array}$ & 0.062 & $\mathbf{0 . 9 0 9}$ & -0.061 \\
$\begin{array}{l}\text { 3. I don't have any worry about money. } \\
\text { 7. I think that I am healthy. }\end{array}$ & 0.037 & $\mathbf{0 . 8 2 3}$ & 0.435 \\
$\begin{array}{l}\text { 8. I think that my physical strength is better } \\
\text { than others' }\end{array}$ & 0.263 & 0.235 & $\mathbf{0 . 8 7 8}$ \\
$\begin{array}{l}\text { Eigen value } \\
\text { Dispersal rate }\end{array}$ & -0.056 & $\mathbf{0 . 7 0 3}$ \\
$\begin{array}{l}\text { Accumulation (\%) } \\
\text { Reliability }\end{array}$ & 2.558 & 1.655 & 1.636 \\
\hline & 36.539 & 23.642 & 23.372 \\
& 36.539 & 60.182 & 83.554 \\
\hline & 0.739 & 0.762 & 0.680 \\
\hline
\end{tabular}

Table 4. The factor analysis and the reliability analysis of recovery resilience

\begin{tabular}{|c|c|c|c|c|}
\hline \multirow{2}{*}{ Questions } & \multicolumn{4}{|c|}{ Recovery resilience } \\
\hline & Self-efficacy & Empathy ability & Impulse control & Self-optimism \\
\hline 22. I believe that I can do well. & 0.853 & 0.320 & 0.005 & -0.023 \\
\hline 24. I think that I am distinguished in coping skills in all areas. & 0.758 & 0.093 & 0.436 & 0.005 \\
\hline 17. I can figure out others' feeling with their facial expression. & 0.069 & 0.933 & -0.035 & 0.062 \\
\hline 19. When my colleague is angry, I can recognize the reason why he or she is angry. & 0.318 & 0.840 & -0.038 & -0.286 \\
\hline 7. When someone is angry at me, I respond to it after listening to it attentively. & 0.320 & -0.117 & 0.867 & 0.116 \\
\hline 8. I trust the words like "A ounce of prevention is worth a pound of cure." & -0.037 & 0.018 & 0.854 & -0.206 \\
\hline 11. I think that there is an uncontrollable situation. & 0.193 & -0.175 & -0.147 & 0.890 \\
\hline 12. It is difficult for me to imagine that I will make a success in my future. & -0.540 & 0.065 & 0.056 & 0.780 \\
\hline Eigen value & 2.019 & 1.979 & 1.949 & 1.274 \\
\hline Dispersion rate & 25.232 & 24.740 & 24.367 & 15.923 \\
\hline Accumulation (\%) & 25.232 & 49.972 & 74.339 & 90.262 \\
\hline Reliability & 0.868 & 0.857 & 0.686 & 0.741 \\
\hline
\end{tabular}


reliability, Cronbach's Alpha, which is the confidence coefficient representing the internal consistency, was calculated. Cronbach's Alpha appeared to be $0.686-0.868$, similar to the level $(0.653$ 0.792 ) of the previous studies. This was judged to be reasonable.

\section{Research procedures and data analysis}

Three Assistance researchers including the author of this paper visited the targeted area and explained precautions, the purpose of questions and contents to the research subjects and distributed questionnaire papers to them. After instructing them to give their response as a self-administration method and questionnaire papers were collected. As a data processing method which was incomplete and unreliable in response were excluded from the analysis. After inputting the data available to the analysis was conducted by SPSS 18.0. As statistical techniques, collected data were processed by t-test, one-way ANOVA, correlation analysis, and multiple regression analysis. The concrete data processing is summarized as follows: First, to verify the composition validity of questionnaire papers, exploratory factor analysis and reliability analysis were conducted. Second, to examine the correlations of variables, correlation analysis was conducted. Third, to analyze the relation- ships of the push factors in the leisure sports participation of the retired elderly, re-socialization, and recovery resilience, the multiple regression analysis was conducted.

\section{RESULTS}

An analysis on the correlation of the push factors in the leisure sports participation of the retired elderly with re-socialization and recovery resilience

To confirm the multicollinearity which can see in the variables of this study, the correlation analysis on all variables were conducted and the study results are shown in Table 5. The analysis results showed that the correlation coefficient of all factors is less than 0.695 , which was lower than the judgment standard of the multicollinearity, 0.80 . Therefore, all factors were identified as the different concepts of composing.

\section{The effect of the push factors in the leisure sports participation on re-socialization}

The study results about the effect of the retired men's participation in leisure sports on re-socialization are shown in Table 6. In

Table 5. The analysis results of correlation

\begin{tabular}{|c|c|c|c|c|c|c|c|c|c|c|}
\hline Division & 1 & 2 & 3 & 4 & 5 & 6 & 7 & 8 & 9 & 10 \\
\hline 1. Psychological stability & 1 & & & & & & & & & \\
\hline 2. Personal relationship & $0.461^{*}$ & 1 & & & & & & & & \\
\hline 3. Health pursuit & 0.092 & -0.112 & 1 & & & & & & & \\
\hline 4. Personal exchange & $-0.627^{*}$ & $-0.395^{*}$ & $0.167^{*}$ & 1 & & & & & & \\
\hline 5. Economic activity & $-0.540^{*}$ & $-0.181^{*}$ & $-0.162^{*}$ & $0.305^{*}$ & 1 & & & & & \\
\hline 6. Social commitment & $-0.608^{*}$ & $-0.292^{*}$ & -0.110 & $0.725^{*}$ & $0.357^{*}$ & 1 & & & & \\
\hline 7. Empathy & $-0.282^{*}$ & -0.028 & 0.035 & $0.221^{*}$ & $0.170^{*}$ & $0.477^{*}$ & 1 & & & \\
\hline 8. Impulse control & $-0.215^{*}$ & 0.025 & $0.695^{*}$ & $0.328^{*}$ & -0.017 & -0.091 & -0.044 & 1 & & \\
\hline 9. Optimism & $0.378^{*}$ & $0.284^{*}$ & $-0.178^{*}$ & $-0.244^{*}$ & $-0.324^{*}$ & $-0.266^{*}$ & $-0.527^{*}$ & -0.110 & 1 & \\
\hline 10. Self-efficacy & $-0.157^{*}$ & 0.018 & $0.346^{*}$ & $0.484^{*}$ & $0.193^{*}$ & $0.335^{*}$ & $0.582^{*}$ & $0.487^{*}$ & $-0.438^{*}$ & 1 \\
\hline
\end{tabular}

${ }^{*} P<0.01$.

Table 6. The effect of the push factors of the leisure sports participation on re-socialization

\begin{tabular}{|c|c|c|c|c|c|c|c|}
\hline \multirow{3}{*}{ Variable } & & \multicolumn{6}{|c|}{ Re-socialization } \\
\hline & & \multicolumn{2}{|c|}{ Personal exchange } & \multicolumn{2}{|c|}{ Economic activity } & \multicolumn{2}{|c|}{ Social commitment } \\
\hline & & $\beta$ & $\mathrm{t}$ & $\beta$ & $\mathrm{t}$ & $\beta$ & $\mathrm{t}$ \\
\hline \multirow[t]{3}{*}{ Push factor } & Psychological stability & -0.604 & $-12.372^{* *}$ & -0.561 & $-10.231^{* *}$ & -0.590 & $-11.304^{* *}$ \\
\hline & Relationship & -0.092 & -1.884 & 0.066 & 1.202 & -0.026 & -0.497 \\
\hline & Health pursuit & 0.213 & $4.876^{* *}$ & -0.103 & $-2.093^{*}$ & -0.058 & -1.249 \\
\hline $\mathrm{R}$ & & \multicolumn{2}{|c|}{0.672} & \multicolumn{2}{|c|}{0.555} & \multicolumn{2}{|c|}{0.611} \\
\hline$R^{2}$ & & \multicolumn{2}{|c|}{0.451} & \multicolumn{2}{|c|}{0.308} & \multicolumn{2}{|c|}{0.373} \\
\hline $\mathrm{F}$ & & \multicolumn{2}{|c|}{$82.196^{* *}$} & \multicolumn{2}{|c|}{$44.480^{* *}$} & \multicolumn{2}{|c|}{$59.426^{* *}$} \\
\hline
\end{tabular}

${ }^{*} P<0.05$. ${ }^{* *} P<0.01$. 
Table 7. The effect of the push factors in leisure sports participation on recovery resilience

\begin{tabular}{|c|c|c|c|c|c|c|c|c|c|}
\hline \multirow{3}{*}{ Variables } & & \multicolumn{8}{|c|}{ Recovery resilience } \\
\hline & & \multicolumn{2}{|c|}{ Empathy ability } & \multicolumn{2}{|c|}{ Impulse control } & \multicolumn{2}{|c|}{ Optimism } & \multicolumn{2}{|c|}{ Self-efficacy } \\
\hline & & $\beta$ & $\mathrm{t}$ & $\beta$ & $\mathrm{t}$ & $\beta$ & $\mathrm{t}$ & $\beta$ & $\mathrm{t}$ \\
\hline \multirow[t]{3}{*}{ Push factors } & Physical stability & -0.358 & $-5.715^{* *}$ & -0.428 & $-10.723^{* *}$ & 0.350 & $5.928^{* *}$ & -0.282 & $-4.727^{* *}$ \\
\hline & Relationship & 0.147 & $2.341^{*}$ & 0.308 & $7.706^{* *}$ & 0.101 & 1.700 & 0.192 & $3.218^{* *}$ \\
\hline & Health pursuit & 0.085 & 1.514 & 0.768 & $21.555^{* *}$ & -0.199 & $-3.770^{* *}$ & 0.394 & $7.402^{* *}$ \\
\hline R & & \multicolumn{2}{|c|}{0.316} & \multicolumn{2}{|c|}{0.796} & \multicolumn{2}{|c|}{0.443} & \multicolumn{2}{|c|}{0.429} \\
\hline $\mathrm{R}^{2}$ & & \multicolumn{2}{|c|}{0.100} & \multicolumn{2}{|c|}{0.634} & \multicolumn{2}{|c|}{0.197} & \multicolumn{2}{|c|}{0.184} \\
\hline $\mathrm{F}$ & & \multicolumn{2}{|c|}{$11.089^{* *}$} & \multicolumn{2}{|c|}{$172.854^{* *}$} & \multicolumn{2}{|c|}{$24.475^{* *}$} & \multicolumn{2}{|c|}{$22.550^{* *}$} \\
\hline
\end{tabular}

${ }^{*} P<0.05 .{ }^{*} P<0.01$.

view of the study results, among sub-factors, it was shown that psychological stability $(\beta=-0.604)$ and health pursuit $(\beta=0.213)$ would have an effect on personal exchanges: Psychological stability $(\beta=-0.561)$ and health pursuit $(\beta=-0.103)$ would have an effect on economic activity while psychological stability $(\beta=-0.590)$ would have an effect on social commitment. In addition, as independent variables, used in the regression analysis, personal exchange, economic activity, and social commitment in the sub-factors of re-socialization can explain the percentage of $45.1 \%$, $30.8 \%$, and $37.3 \%$ of the total variance respectively.

\section{The effect of the push factors in the leisure sports participation on recovery resilience}

The study results about the effect of the push factors of the retired men's participation in leisure sports are shown in Table 7. Investigating the results, it was revealed that psychological stability ( $\beta=-0.358)$, and personal relationships $(\beta=0.147)$ would have an effect on empathy ability; psychological stability $(\beta=-0.428)$, personal relationships $(\beta=0.308)$, and health pursuit $(\beta=0.768)$ on impulse control; psychological stability $(\beta=0.350)$, health pursuit $(\beta=-0.199)$ on optimism; and psychological stability $(\beta=-0.282)$, personal relationships $(\beta=0.192)$, and health pursuit $(\beta=0.394)$ on self-efficacy. As independent variables used in the regression analysis, empathy ability, impulse control, optimism, and self-efficacy among the sub-factors of recovery resilience explain the percentage of $10.1 \%, 63.4 \%, 19.7 \%$, and $18.4 \%$ of the total variance.

\section{DISCUSSION}

In our society, a wide range of problems involving the retired elderly are emerging on the surface. At this point, we can draw the specific discussion based on the analysis results about the effect of the push factors in the leisure sports participation on re-so- cialization and recovery resilience.

First, it was revealed that psychological stability among the push factors in the leisure sports participation would have a significant effect on re-socialization, while health pursuit would have a significant effect on personal exchange and economic activities among the sub-factors of re-socialization.

In terms of the effect of psychological stability on the re-socialization factors, the findings of this study are consistent with the study of Jung and Won (2010) to some degree in that the retired elderly who lose the fixed income source and have the less interaction with colleagues due to the retirement pursue psychological stability through the activities of leisure sports, and thereby they can overcome their loneliness and a sense of isolation by increasing the affiliation with the group. On top of it, the study results that the satisfaction of the elderly participation in sports activities would have a positive effect on the quality of life by addressing the problem of loneliness and the results of Ko (2009) revealed that the motivational factors of psychological stability would have a positive effect on re-socialization, which are parallel to the results of this study.

In sequence, the findings of this study that health pursuit factors would have a significant effect on personal exchange and economic activity partially corresponds to those of Cho and Kim (2008), and Jung and Won (2010) that the motivational factors of the retired elderly in health pursuit would have a positive effect on personal exchange. Also, Ko (2009) revealed that the motivational factors of physical strength and social relationships would have a positive effect on health pursuit factors. Along with these findings, natural social relationships or opportunity to establish relationships through the leisure sports participation would have an effect on the improvement of life quality, which is similar to the findings of this study, demonstrating that the participation in leisure sports would have an effect on physical stability and health pursuit. 
Therefore, if the retired elderly pursue psychological stability and health as the push factors in the leisure sports participation, it will have a positive effect on happier and more relaxed re-socialization. In particular, psychological stability will be conducive to re-socialization of the retired elderly who feel the loss of role, a sense of isolation, or alienation due to the retirement because of the expansion of personal exchange and economic activity. Second, it was demonstrated that psychological stability among the push factors in the leisure sports participation would have a significant effect on the recovery resilience of the retired elderly; personal relationships would have a significant effect on empathy ability, impulse control, and self-efficacy among the sub-factors of recovery resilience; and health pursuit would have a significant effect on impulse control, optimism, and self-efficacy.

In the first place, the findings that psychological stability would have an effect on all factors of recovery resilience appear to correspond to those of Jung and Won (2010). The studies mentioned above back up this study by revealing that the retired elderly could overcome helplessness and alienation due to psychological stability, leading to a happy life. In this context, through leisure sports activity, the retired elderly could be recovered from a sense of loss, and the quality and recovery resilience of their life could be improved by performing the role of a social person because of the fulfillment of a desire in life. In addition, the study of Choi and Lee (2012) showed that the leisure sports participation of the elderly would have a positive effect on psychological stability, depression, and recovery resilience, while the study of Choi (2007) revealed that leisure sports help people minimize a sense of isolation and maintain the positive emotions.

These studies indicate that leisure sports activity of the retired elderly can change hardships in life into a good luck by influencing the recovery resilience in pursuit of psychological stability when the retired elderly are detached from their affiliated group or lose their role.

In the second place, it was demonstrated that personal relationships would have a significant effect on empathy ability, impulse control, and self-efficacy among the sub-factors of the recovery resilience. This reveals that the push factors in personal relationships would have a significant effect on the empathy ability, which understands others' feeling, mental status, and internal experience, impulse control, encouraging willingness to change the habit of mind for a better self and self-efficacy, which make people see as a competent, capable, and efficient person. The study of Ko (2009) and the study of Jung and Won (2010) have something in common with the findings of this study in that leisure sports activity can help people establish close relationships with others and play a social role with active civic consciousness. Also, a study on the participation of the elderly in dance sports, life stress, and physical respect conducted by Yeom (2008) revealed that the elderly who are involved in leisure sports activity receive less stress and subsequently their self-efficacy is high. Taken together, the studies, mentioned above demonstrate that the pursuit of improving personal relationships through leisure activities have a positive effect on empathy ability, impulse control, and self-efficacy of the retired elderly.

The findings of Jung and Won (2010) are parallel to those of this study, demonstrating that health pursuit would have a significant effect on impulse control, optimism, and self-efficacy. These studies reveal that the factors of the health pursuit of leisure sports activity had a positive effect on a happy life of the retired elderly by enabling them to overcome the helplessness and loneliness of the elderly, and the retired elderly regained their confidence in their life and played a role of a social person actively by fulfilling their desire in life. In addition, Schike (1991) supports the findings of this study by revealing that recovery resilience of the retired elderly was improved and the elderly experienced positive emotions by overcoming a sense of isolation in their social life through leisure sports activity.

These results have grounds for the fact that the retired elderly can solve their current problems by enhancing their impulse control, optimism, and self-efficacy through the push factors of the leisure sports participation. In particular, the loss of a role in society and family and the feeling of isolation or alienation can be connected to a lot of social problems and lower the value of being. In this regard, the effect of recovery resilience, prolonging life span, improving the quality of the life, and changing adversity into a good luck is considered to be significant.

\section{CONFLICT OF INTEREST}

No potential conflict of interest relevant to this article was reported.

\section{ACKNOWLEDGMENTS}

The study of this paper was conducted under the support of the National Research Foundation of Korea with the financial resources of the government (Humanities and Social Science Basic Studies) (NRF-2011-35C-G00296). 


\section{REFERENCES}

Bae JH. A study on the continual physical activity participation of the female elderly and re-socialization. Korea Sports Res 2004;15(4):869-879.

Cho MT, Kim SD. The effect of the retired men's participation motive in sports activity on re-socialization. J K SSLS 2008;32:637-649.

Choi JJ, Yun YJ, Park JH. The Effect of the Social Dance Program on the Leisure and Life satisfaction of the female elderly. J KAHPERD 2007; 46(2):317-326.

Choi MR, Lee YC. The Buffering effect of recovery resilience in the relationship between life stress and depression according to the elderly participation in leisure activity. J KAHPERD 2012;51(1): 75-90.

Choi SB. The effect of the social support and self-esteem of leisure sports participation on psychological well-being. J KAHPERD 2007;46(3): 339-350.

Jung HJ, Won YS. The participation motivation of the retired male men in leisure sports on re-socialization and happy life. J Korea Soc Study Physic Edu 2010;15(3):209-220.

Kim DG, Yun SY. The relationships of the elderly participation in leisure sports with social support, sports satisfaction and loneliness. J KAHPERD 2007;46(6):345-356.

Kim HS, Gang M. The effect of the life gymnastics program participation of the elderly leisure welfare centers on psychological well-being, J KAHPERD 2006;45(6):91-104.

Ko YH. The effect of the retired men's participation motivation in leisure sports program on re-socialization and social role. J K SSLS 2009;37:
811-820.

Lee DS, Keon P. The relationships of the elderly leisure activity types with leisure satisfaction, leisure immersion and isolation. J KAHPERD 2003;42(3):355-364.

Lee ES, An CW. The effect of the elderly participation in leisure sports on successful aging: focusing on the mediating effect of recovery resilience. J KAHPERD 2010;49(4):325-337.

Lee HW. The mediating effect of recovery resilience in the relationship between the leisure activity participation of the korean elderly and well-being. Korean Soc Exer Rehabil 2012;8(2): 3-17.

Park JG, Im RH, Choi DM. The relationship between the leisure activity types of the elderly and depression. J KAHPERD 2007;46(1):577-588.

Schike J M. Slowing the aging process with physical. J Gerontol Nursing 1991;17(6):4-8.

Seo JG. The relationships of the elderly participation in leisure activity with social network and social support. J KSSS 2000;13(1):403-423.

Seong NH, Baek JW. The relationships of the leisure activity participation with social support, self-esteem, and stress. Korea Sports Res 2004; 15(1):3-17.

Shin WY, Kim MG, Kim JH. The development of test Index of recovery resilience and the verification of validity. A Study on the Korean Youth. 2009; 20(4):105-131.

Yeom BH. The causal relationship of the life style of the elderly who participate in dance sports with physical respect and social h-ppiness. Korea Sports Res 2008;19(4):3-11. 